\title{
Biochemical regulation of condylar growth and remodelling - An overview
}

\author{
Vikash Kumar', Tulika Tripathi ${ }^{2, *}$, Shilpa Kalra ${ }^{3}$, Priyank Rai ${ }^{4}$ \\ ${ }^{1}$ PG Student, ${ }^{2}$ Senior Professor and Head, ${ }^{3}$ Senior Research Associate, ${ }^{4}$ Professor, Dept. of Orthodontics \& Dentofacial \\ Orthopedics, Maulana Azad Institute of Dental Sciences, New Delhi, India
}

\section{*Corresponding Author: Tulika Tripathi}

Email: drtulikatripathi@yahoo.com

\begin{abstract}
Condylar cartilage has been classified as an articular cartilage. It has been further categorized as a secondary cartilage. This characterization is based upon its delayed development, unique histological features and adaptive capability to external stimuli. This adaptive and remodelling capacity of condylar cartilage to forward positioning of mandible forms basis of orthodontic functional treatment.

Molecular and genetic control of epiphyseal cartilage has been well documented. However condylar cartilage has received attention only in last few decades. Condylar cartilage growth has partial genetic and strong epigenetic control. Epigenetic control includes systemic factors and local factors, such as growth factors and mechanical stimuli. Various growth factors and transduction mediators bring about natural development and adaptive remodelling of condylar cartilage. Growth factors are large group of polypeptide molecule which exerts its effect by paracrine or endocrine mechanism. Growth factors can exert various effects depending on the type of receptor it interacts. Depending upon the receptor it can bring about mitotic, hypertrophic or anti proliferative effect. These molecular controls play important role in growth and homeostasis.

This article is an attempt to assimilate available knowledge and current concept regarding molecular and genetic control of condylar growth.
\end{abstract}

Keywords: Condylar growth, Remodelling, Growth factor.

\section{Introduction}

Development of orofacial complex is hugely guided by mandibular condyle, which brings it under special attention of orthodontist. ${ }^{1}$

Mandibular condylar cartilage is classified as articular cartilage which can be further sub classified as secondary cartilage. It distinguishes itself from any other cartilage on the basis of its embryonic origin, post-natal growth mode, and histological structures. Most unique feature of condylar cartilage lies in its ability to execute adaptive remodelling under the influence of external stimuli during or after natural growth. ${ }^{2}$ During orthodontic functional therapy mandibular advancement or bite jumping provides necessary stimuli to bring about adaptive remodelling of condylar cartilage. Thus adaptive remodelling forms fundamental rationale of orthodontic functional therapy. The adaptive remodelling of condylar cartilage progresses with the bio molecular pathway initiating from chondrogenesis and concluding with osteogenesis.

\section{Unique and Distinguishing Features of Condylar Cartilage}

The biological features of articular chondrocytes differ from epiphyseal chondrocytes. Unlike epiphyseal cartilage, articular cartilage present chondrocyte throughout postnatal life and retains its morphological and biosynthetic features. ${ }^{3}$ whereas, the epiphyseal chondrocytes is present only in puberty, during which they participate in the endochondral ossification by exhibiting phenotypic changes. ${ }^{4}$ Even though condylar cartilage is classified as articular cartilage, it stands out because of its unique capability to undergo adaptive changes in response to external stimuli unlike other articular cartilages. ${ }^{5}$

Condylar cartilage distinguishes itself in histological structures from both epiphyseal and articular cartilage in the following respects:

Two phases of gene expression patterns of chondrocytes during condylar growth are maturation and mineralization. ${ }^{6}$ Pre-chondroblast is formed by mesenchyme differentiation, which is first step of chondrocyte maturation. End stage of chondrocyte phenotypic expression is characterized by matured hypertrophic chondrocytes.

\section{Zones of Condylar Cartilage}

Articular Zone: This zone forms outer most covering of the articular surface. It is characterized by densely packed collagenous fibers with fibroblasts. The periosteum of condylar neck shows continuity with dense fibrous tissue and exhibits parallel arrangement of the fibroblasts with respect to surface of condylar head. Articular zone presents a layer of mesenchymal cells underneath fibrous tissues. ${ }^{7}$

Resting Zone: This zone lies beneath articular zone and forms most superficial part of condylar articular cartilage. Resting zone is characterized by small chondrocyte, lesser chondroid matrix and high mitotic potential reflected by high nuclei-to-cytoplasm ratio. ${ }^{8}$

Proliferative Zone: Mature cartilage with abundant chondroid matrix is seen in proliferative zone. This zone is characterized by large chondrocytes enveloped in lacunae, with a clear zone crammed in between them. Absence of orderly formation or column-like arrangement of chondrocyte in this zone is a distinctive 
aspect of condylar articular cartilage in comparison to epiphyseal cartilage. ${ }^{9}$

Hypertrophic Zone: This zone is characterized by highly mature chondrocyte and first sign of calcification. Chondroid matrix in this layer contains high density of collagen fibres and is continuous with underneath osteoid matrix. There is increase in size of lacunae which encloses chondrocyte, along with degeneration of few chondrocyte presenting a pyknotic appearance. ${ }^{10}$

Erosive Zone: Ending of chondrogenesis and beginning of osteogenesis is the hallmark of erosive zone. In this zone cartilage and connective tissue of the marrow cavity are in direct contact. Formation of Cartilaginous spicules which undergoes interim calcification is preceded by chondrocytic apoptosis and breakdown of cartilage. Angiogenesis begins at this stage along with infiltration of degenerated cartilage. Formation of randomly arranged bony trabeculae is seen in this zone. ${ }^{8,11}$

\section{Condylar Cartilage- A Secondary Cartilage}

Condylar cartilage is defined as secondary cartilage as it appears later in development and is independent of chondroskeleton. Few salient features that determine condylar cartilage as secondary cartilage are:

Delayed Origin: According to Suda et al., 1999 and Meikle, 2002 the temporomandibular joint is formed after most of the synovial join during pre-natal development. ${ }^{10,11}$ In another experimental study, immunolocalization of types II and X collagen in the foetal mouse mandible where not positive till $15^{\text {th }}$ day of pregnancy. This delayed articulation between temporal bone and the mandible establishes late development of condylar cartilage which is indicative of its secondary origin, in comparison to primary cartilage which forms earlier. ${ }^{12}$

Ontogenetic Development: Primary cartilages are formed within the mesenchymal blastema which later develops into the future mandible. However, cartilage formation in the condylar process, the coronoid process, the symphysis, and the gonial area begins as a secondary event subsequent to formation of primary cartilages. Except condylar cartilage others disappear around birth. Articular function of temporomandibular joint plays homeostatic role in sustaining condylar secondary cartilage within the membranous components of the condylar process throughout our life. $^{13}$

Adaptive Potential: Thin perichondrium covers primary cartilages, whereas secondary cartilage is covered by a fully developed mesenchymal tissue layer. This mesenchymal covering of the condyle is responsible for its adaptive potential. ${ }^{14,15}$

Post-natal Growth Regulation: During growth, Primary epiphyseal cartilage reacts primarily to systemic growth stimuli such as hormones whereas; condylar cartilage only secondarily follows these overall stimuli after additional modulation by local growth factors. ${ }^{14,16}$

\section{Condylar Growth and Remodelling}

Stage I- Chondrogenesis: Integral part of chondrogenesis is phenotypic and morphologic changes of chondrocyte, which is expressed as chondrocytic maturation and results in endochondral bone formation. Various growth factors regulate chondrogenesis and the consequent endochondral bone formation observed at the mandibular condyle. ${ }^{17}$ The regulation of cell proliferation, differentiation, and maturation during chondrogenesis is carried out by various extracellular growth factor, which are bone morphogenetic proteins (BMP), parathyroid-hormone-related peptide (PTHrP), insulin-like growth factors (IGF), transforming growth factors (TGF), fibroblast growth factors (FGF), and members of the hedgehog (Ihh) and Wnt gene families. Transduction of these regulatory signals from growth factors are mediated by transcription factors (Sox family and core-binding factor alpha) within the developing mesenchymal cells and chondrocytes, resulting in changed gene expression. ${ }^{18}$

\section{Factors Regulating Mesenchyme Chondrogenic Differentiation}

L-Sox5, Sox6, and Sox 9 which belong to the Sryrelated family of HMG box DNA-binding proteins are master transcription factors implicated in differentiation of mesenchymal cells into chondrocytes. ${ }^{19}$ Inactivation of Sox9 gene after mesenchymal condensations leads to arrest of differentiation of condensed mesenchymal cells into chondrocytes. ${ }^{20}$ Sox9 utilizes cAMP-response element-binding protein (CREB) to exert its effects. The co-activators of Sox9 for cartilage tissue-specific gene expression and chondrocyte differentiation are CBP and p300..$^{21}$ Sox9 is up regulated by Parathyroid hormone-related protein (PTHrP) $)^{22}$ and found in abundance at sites of mesenchymal condensation. ${ }^{23}$

\section{Factors Regulating Mesenchyme and Chondrocyte Proliferation}

Fibroblast Growth Factor (FGF): An increased proliferation of the undifferentiated mesenchymal cells is brought about by FGF-2. Local administration of this protein in articular cartilage even with full-thickness defects can bring about renewal of chondrogenesis. ${ }^{24}$ In contrast to FGF-2, BFGF (basic fibroblast growth factor) inhibits proliferation of chondrocytes. Downregulation of the transcription factors, namely PTHrP and Cbfa1 by BFGF results in inhibition of mesenchymal proliferation. ${ }^{25}$

Transforming Growth Factor and Insulin like Growth Factor (TGF and IGF): Chondrocytic proliferation and early formation of cartilage is seen at fracture healing site by local application of IGF-I and TGF-beta. ${ }^{26}$ In another experimental study, local administration of IGF-I to the bilateral mandibular 
articular cavities in rats produced increase in the thickness of the condylar cartilage and enhanced proliferation of chondrocytes. ${ }^{17}$ The mitogen-activated protein (MAP) kinases activated by TGF-betas, have been shown to promote cartilage-specific gene expression. $^{27}$

Proliferating Cell Nuclear Antigen (PCNA): PCNA is used as a marker for cell proliferation as it is required for eukaryotic chromosomal DNA replication where it works in tandem with DNA polymerase delta. ${ }^{28}$ PCNA is found in nuclei of chondroblasts of the reserve cell layer and the upper hypertrophic layer. Increase in chondrocyte mitosis in condylar cartilage is indicated by a concomitant increase in percentage of PCNApositive cells. ${ }^{29}$ PCNA is an integral part of various cellular processes such as DNA repair, DNA methylation, chromatin assembly and thus also plays a role in cell cycle regulation. ${ }^{28}$

D-type Cyclins: D-type cyclins, member of the retinoblastoma family, are expressed in proliferating and differentiating chondrocytes. ${ }^{30}$ D-type cyclins control cell-cycle activation primarily the progression through the G1 phase of the cell cycle. Binding of Dtype cyclins leads to activation of the cyclin-dependent kinases Cdk4 and Cdk6. Cell-cycle progression is thus induced by the subsequent expression of S-phase genes. ${ }^{31}$

Wnt Family: Regulatory role of Wnt in chondrocytic differentiation has been recently shown. Wnt5a and Wnt5b coordinate chondrocyte proliferation, whereas cyclin D1, p130 and chondrocyte-specific Col2a1 expression have role in chondrocyte differentiation. ${ }^{30}$ Wnt-1 and Wnt-7a has proliferative effects on prechondrogenic mesenchyme, and an inhibitory effect on differentiation at the late blastema stage. ${ }^{33}$

Bone Morphogenetic Protein (BMP): BMP-2 and BMP -4 play regulatory roles in the process of endochondral ossification. $^{34}$ BMP-2-induced chondrogenesis is inhibited by Wnt signaling, which indicates an antagonism between Wnts and BMP-2 during mesenchymal condensation.

\section{Factors Regulating Chondrocyte Maturation and Differentiation}

Parathyroid Hormone-Related Protein and Indian Hedgehog (PTHrP and Ihh): Proliferation and maturation of chondrocyte is regulated by two signalling molecule namely Ihh and PTHrP. ${ }^{35}$ Ihh stimulates chondrocytic proliferation, whereas it inhibits hypertrophy and ossification via PTHrP. ${ }^{35,36} \mathrm{Ihh}$ and PTHrP forms negative-feedback loop through which it regulates endochondral ossification. ${ }^{37}$ this has been substantiated by an experimental study in which deletion of PTHrP in mice lead to development of dyschondroplasis, resultant from premature maturation of chondrocyte. ${ }^{38}$ Regulation of cartilage hypertrophic differentiation is brought about by TGFbeta- 2 acting as a signal relay between Ihh and PTHrP. ${ }^{39}$
Core Binding Factor Alpha and Runt-Related Transcription Factor 2 (Cbfa and Runx 2): Cbfa not only plays important role in osteoblastic differentiation but also its expression increases with increasing chondrocyte maturation. ${ }^{40}$ Dual action of chondrocytic maturation and degradation by Cbfa1 controls the postnatal growth of the condyle. ${ }^{41}$ Runx 2 is another important transcription factor required for chondrocyte maturation. This has be substantiated by an experimental study in which depletion of Runx2 resulted in impairment of chondrocyte hypertrophy and differentiated phenotype in chondrocytes in vitro. ${ }^{42,43}$

Wnt: Wnt has regulatory role in chondrocytic differentiation. ${ }^{44}$ Wnt- 1 and Wnt-7a causes a severe block in differentiation of chondrocyte at the lateblastema/early-chondroblast stage. ${ }^{33}$ Blocking of the initiation of chondrogenesis and acceleration of terminal chondrocyte differentiation is implicated to Wnt $4 .{ }^{45}$ Wnt-7a stimulates transcriptional activity of beta-catenin which induces differentiation of articular chondrocyte. ${ }^{46}$

Stage II- Transition from Chondrogenesis to Osteogenesis: Transition from chondrogenesis to osteogenesis takes place in the erosive zone of hypertrophic cartilage. Alkaline phosphatase is synthesized by hypertrophic chondrocytes and at the same time, calcification of cartilage matrix take place which progressively stops the diffusion of nutrients. ${ }^{11,47}$ During growth maximum level of BALP (bone specific alkaline phosphatase) is seen during CVMI stage 3. As alkaline phosphatase is expressed by hypertrophic chondrocyte, maximum level of its expression must be concomitant with maximum growth. ${ }^{48}$ This eventually leads to death of chondrocyte, breakdown of matrix and formation of increasing large cavities by confluence of neighbouring lacunae. Presence of empty lacunae and discontinuity of the mineralised intercellular partitions provides space for vascular invasion. This angiogenesis causes influx of osteoprogenitor and bone marrow stem cells which eventually differentiate into osteoblasts..$^{5,49}$ Osteoblasts lay down osteoid on framework provided by the spicule and remnants of lacunar cartilage. Subsequent osteoid calcification results in new bone formation. This new bone formation occur along naked ends of the mineralised cartilage strands, which eventually leads to union condylar cartilage to osseous mass of the ramus. ${ }^{5,50}$

Hypertrophic cartilage progresses to endochondral ossification by Invasion of capillary endothelium which plays a critical role in initiating the transistion. ${ }^{51}$ In an experimental study adaptive chondrogenesis of condylar cartilage was initiated by repositioning of the mandible in rats, which verified the association between penetration of vasculature and emergence of osteogenesis. Immunolocalization of capillary endothelium showed strong immunoreactivity in erosive zone and in the bony tissue underneath, where neoangiogenesis took place. $^{52}$ Other studies by 
quantitative imaging analysis have shown similar result with regard to neovascularisation of the erosive zone, which substantiate the association of vascularization and new bone formation. ${ }^{53,54}$

\section{Stage III- Osteogenesis}

Adaptive Remodeling: Condylar cartilage has a special multi directional capacity for growth and remodelling. Unlike articular cartilage, condylar cartilage shows adaptive remodelling to mechanical or positional change by alteration or regeneration of chondrogenesis and subsequent endochondral ossification. ${ }^{55}$ Hence, changes in condylar repositioning, articular functioning and mechanical loading results in condylar remodelling. This is the most intriguing biological aspect and differentiates it from any other synovial or epiphyseal cartilage. ${ }^{56,57}$

Condylar remodelling is an important factor influencing the mandibular morphology during or after natural growth. Role of condylar adaptation in reshaping the morphology of the mandible is explained by various studies which have shown mandibular advancement with orthodontic functional appliances, even beyond normal growth by enhancing condylar growth. ${ }^{58}$

Various studies have shown condylar remodelling in the post-natal growth period as well as after growth has ceased. Rabie et $\mathrm{al}^{59}$ have shown accelerated maturation of chondrocyte and subsequent enhanced endochondral ossification with forward positioning of condyle in growing rats. Other studies by Chayanupatkul et $\mathrm{al}^{60}$ and Rabie et $\mathrm{al}^{59}$ have shown condylar repositioning in adult rats by reactivation of chondrogenesis in condylar cartilage and increased bone formation.

Endochondral Ossification in Relation to Condylar Repositioning: The reason for adaptive remodeling of condylar cartilage is still under investigation. Condylar repositioning relative to glenoid fossa constitutes an important trigger for condylar cartilage adaptation. ${ }^{58}$ Bite jumping produce condylar repositioning which initiate condylar remodelling and forms the basis of orthodontic functional therapy. Experimental studies in rats have been conducted to identify the cellular response of condylar cartilage during mandibular advancement. ${ }^{58,59,61}$ Mandibular advancement leads to stretching and directional orientation(toward the direction of the pull) of the mesenchymal cells in the articular zone of condylar cartilage ${ }^{52,62}$ This directional orientation and physical stretching of mesenchyme cells induce its proliferation and differentiation. ${ }^{62}$ This observation has been further substantiated by a recent study on Ihh, a transducing mediator implicated for mesenchymal proliferation which eventually result in endochondral ossification. ${ }^{63}$

The influence of mandibular repositioning or mechanical loading has been centre of focus of several studies. Increase in compressive loading of condylar cartilage retards the growth, whereas decrease in compressive loading has enhancing growth effect. ${ }^{62,63}$ This indicates that when condyle contacts the fossa, it would slow the maturation process and consequently defer endochondral ossification in condylar cartilage. Deviation of posterior part of the condyle from the fossa leads to accelerated maturation of the cartilage at that point ${ }^{57,65}$ Hence, It can be safe to state that condylar unloading stimulates condylar growth, while articulating function, in contrast, slows condylar growth. This conclusion is in agreement with the observation that absence of articulating function in the mandibular jaw joint would lead to the cartilage maturation and replacement by bone. ${ }^{66,67}$

The reasoning behind phenotypic shift of chondrocyte due to mechanical unloading can be attributed to multipotent pre-chondroblast of condylar cartilage. In the absence of articulating function, chondrocyte switch their bio molecular pathway toward the direction of osteoblasts leading to increase in growth. ${ }^{66,68}$

Articulating function of condyle keeps the cartilage tissue young and adaptive for the purpose of enabling chondrogenesis to continue. Lack of articulating function would lead to rapid hypertrophy of chondrocyte which would eventually end in bone formation. This reflects a unique role of articulating function which is maintenance of condylar articular cartilage $^{5,65,69}$ In comparison to post-natal cartilage, pre-natal cartilage shows greater distance between the maturation front and the pre-chondroblast cell layer. This delays maturation process to reach the prechondroblast layer. Hence, pre-natal condylar cartilage is able to continue its growth without articulating function for a longer period than is the post-natal condylar cartilage..$^{70,71}$

The shape of condyle is under the influence of natural growth. Unlike the posterior part of the condyle, anterior part does not participate in articulation; hence it shows faster maturation and resultant osteogenesis. However, slow maturation and continuation of proliferation is seen in posteror part of condyle due to compressive mechanical loading. This reaction leads to an expansive growth in the anterior part of the condyle. $^{72}$

The Expression of Growth Factors during Adaptive Remodeling of Mandibular Condylar Cartilage: Change in postural position of mandible leads to enhance signalling of growth factors, which in turn causes alteration in the proliferation and growth of the mandibular condylar cartilage. ${ }^{62,73}$

Insulin Like Growth Factor and Fibroblast Growth Factor (IGF and FGF): In an experimental study, lateral functional shift of the mandible by intra-oral appliance in rats produced increased expression of IGF1, FGF-2 and their receptors IGF-1r, FGFr1, 2, 3 on protruded than non-protruded side. ${ }^{72}$ In another rat model study in which the mandible was advanced by 
use of a propulsive appliance lead to increased expression of IGF1, IGF-2 and PCNA. ${ }^{73}$

Maximum increase in IGF-1 is seen in serum and urine during transition and decleration stage of CVMI. As IGF is responsible for mesenchymal proliferation, so it can be safely stated that maximum adaptation and growth of condyle would be seen in CVMI 3 and 4 stage. $^{73,74}$

Vascular Endothelial Growth Factor (VEGF): Bite jumping evokes increased VEGF expression, which solicits a sequence of cellular events leading to increased vascularization. The highest acceleration of vascularization precedes new bone formation. ${ }^{53}$ Second advancement in stepwise mandibular advancement leads to greater VEGF production compared to single step group, which indicate amplitude of mechanical loading of condylar cartilage also exerts a significant effect on the production of VEGF by chondrocytes. ${ }^{54}$

Parathyroid Related-Protein (PTHrP): Mandibular advancement leads to PTHrP expression which overlaps with the retardation of chondrocyte hypertrophy. Hence, it was inferred that PTHrP expression retards chondrocytic maturation, which in turn allocate the provision for future growth by promoting mesenchymal cell differentiation ${ }^{61}$

Sox9: Increase in Sox9 expression and the amount of newly formed bone were observed during mandibular advancement by Quantitative assessment. Hence, the conclusion was drawn that functional appliance therapy accelerates and enhances condylar growth by accelerating the differentiation of mesenchymal cells into chondrocytes, which leads to formation of early and increased amount of chondroid matrix. ${ }^{58}$

Type X Collagen: Hypertrophic cartilage expresses type $\mathrm{X}$ collagen, which indicates its role in the terminal stage of chondrocyte maturation. ${ }^{77}$ There is increased production of type $\mathrm{X}$ collagen with mandibular advancement which provides an easily resorb able fabric in comparison to type II collagen for the deposition of bone matrix and regulation of calcification. ${ }^{78,79}$

Overview of various growth factors and other transduction mediators is given in Table 1

Table 1

\begin{tabular}{|l|l|}
\hline \multicolumn{1}{|c|}{$\begin{array}{c}\text { Growth factors/other transduction } \\
\text { mediators }\end{array}$} & \multicolumn{1}{c|}{ Role in condylar growth and remodelling } \\
\hline Indian hedgehog & $\begin{array}{l}\text { Promotes chondrocytic proliferation } \\
\text { Regulates chondrocytic hypertrophy and maturation via PTHrP }\end{array}$ \\
\hline Parathyroid related-protein & Inhibits chondrocyte hypertrophy and maturation \\
\hline Transforming growth factor & Inhibits chondrocyte hypertrophy and maturation \\
\hline Fibroblast growth factor & $\begin{array}{l}\text { Promotes chondrocytic proliferation } \\
\text { Inhibits chondrocyte terminal differentiation }\end{array}$ \\
\hline Insulin like growth factor & Promotes chondrocyte proliferation and matrix formation \\
\hline Vascular endothelial growth factor & $\begin{array}{l}\text { Promotes neoangiogenesis } \\
\text { Proliferation and migration vascular endothelial cells }\end{array}$ \\
\hline Platelate derived growth factors & $\begin{array}{l}\text { Mitogenic for connective tissue cells } \\
\text { Stimulate chondrocyte differentiation }\end{array}$ \\
\hline Connective tissue growth factor & $\begin{array}{l}\text { Stimulates proliferation, hypertrophy and maturation of } \\
\text { chondrocyte }\end{array}$ \\
\hline $\begin{array}{l}\text { core binding factor alpha and runt-related } \\
\text { transcription factor2 }\end{array}$ & $\begin{array}{l}\text { Regulates chondrocyte hypertrophy, cartilage matrix calcification, } \\
\text { osteoblast differentiation and osteoclast function }\end{array}$ \\
\hline Bone morphogenetic protein & Regulatory role in endochondral ossification \\
\hline WNT & Regulates chondrocyte differentiation \\
\hline D-type cyclin & Rate limiting and progression through G1 phase of cell cycle \\
\hline SOX9 & $\begin{array}{l}\text { Promotes type II collagen synthesis } \\
\text { Up regulated by PTHrP }\end{array}$ \\
\hline Type X collagen & Facilitates easy matrix resorption and calcification \\
\hline IL-1 and TNF $\alpha$ & Activate catabolic pathway in cartilage \\
\hline IL-4, IL-10 and IL-13 & Anabolic pathway in cartilage \\
\hline
\end{tabular}

\section{Conclusion}

Condylar growth is orchestrated by cascade of various growth factors and other regulatory factors. Adaptation potential of mandibular condyle under mechanical loading forms the basis of orthodontic functional therapy. Mandibular loading by compression of condylar cartilage leads to retardation of growth; whereas stretching of condylar cartilage produce growth stimulation. Holistic approach towards understanding of various bio-chemical mediators of growth forms basis of future growth modulation therapy. 


\section{References}

1. Enlow DH. Bone and cartilage. In: Enlow DH (Ed). Facial growth ( $3^{\text {rd }}$ ed $)$. Philadelphia: WB saunders co. 1990. pp. 48-59.

2. Shen $\mathrm{G}$, Darendeliler MA. The adaptive remodeling of condylar cartilage - a transition from chondrogenesis to osteogenesis. J Dent Res. 2005;84(8):691-9.

3. Roberts WE, Hartsfield Jr JK. Bone development and function: genetic and environmental mechanisms. Semin Orthod. 2004;10:100-122.

4. Fawcett DW. Concise histology. New York: Chapman and Hall.1997.

5. Garant PR. Oral cells and tissues. Chicago, IL: Quintessence. 2003.

6. Inoue H, Nebgen D, Veis A. Changes in phenotypic gene expression in rat mandibular condylar cartilage cells during long-term culture. J Bone Miner Res. 1995;10(11):1691-7.

7. Bergman RA, Afifi AK, Heidger PM. Histology. Philadelphia: Saunders.1996.

8. Shen G, Rabie AB, Hägg U, Zhao Z. Expression of type $\mathrm{X}$ collagen in condylar cartilage during mandibular protrusion. Hua Xi Kou Qiang Yi Xиe Za Zhi. 2000;18(2):78-80.

9. Zhao Z, Rabie AB, Urban H, Shen G. Image analysis of condylar cartilaginous adaptation to mandibular protrusion in rats. Hua Xi Kou Qiang Yi Xue Za Zhi. 1999;17(2):155-8.

10. Suda N, Shibata S, Yamazaki K, Kuroda T, Senior PV, Beck F, Hammond VE. Parathyroid Hormone-Related Protein Regulates Proliferation of Condylar Hypertrophic Chondrocytes. J Bone Miner Res. 1999;14(11):1838-47.

11. Meikle MC. Craniofacial development, growth and evolution. Bateson; 2002 Apr 1.

12. Shibata S, Fukada K, Suzuki S, Yamashita Y. Immunohistochemistry of collagen types II and $\mathrm{X}$, and enzyme-histochemistry of alkaline phosphatase in the developing condylar cartilage of the fetal mouse mandible. The Journal of Anatomy. 1997;191(4):561-70.

13. Dibbets JMH. Introduction to the temporomandibular joint. In: Facial growth. Enlow DH, editor. Philadelphia: Saunders.1990. pp. 149-163.

14. Enlow DH. The condyle and facial growth. In: The temporomandibular joint: a biological basis for clinical practice. Sarnat BG, Laskin DM, editors. Philadelphia: Saunders. 1992 pp. 48-59.

15. Delatte M, Von den Hoff JW, Van Rheden RE, KuijpersJagtman AM. Primary and secondary cartilages of the neonatal rat: the femoral head and the mandibular condyle. Eur J Orthod. 2004;112(2):156-62.

16. Sperber GH, Gutterman GD, Sperber SM. Craniofacial development. Hamilton, Ontario: BC Decker.

17. Itoh K, Suzuki S, Kuroda T. Effects of local administration of insulin-like growth factor-I on mandibular condylar growth in rats. J Med Dent Sci. 2003;50(1):79-85.

18. Shum L, Nuckolls G. The life cycle of chondrocytes in the developing skeleton. Arthritis Res. 2001;4(2):94.

19. Lefebvre V, Behringer RR, De Crombrugghe B. L-Sox5, Sox6 and Sox 9 control essential steps of the chondrocyte differentiation pathway. Osteoarthritis and Cartilage. 2001;9:S69-75.

20. De Crombrugghe B, Lefebvre V, Behringer RR, Bi W, Murakami S, Huang W. Transcriptional mechanisms of chondrocyte differentiation. Matrix Biol. 2000;19(5):38994.

21. Tsuda M, Takahashi S, Takahashi Y, Asahara H. Transcriptional co-activators CBP/p300 regulates chondrocyte specific gene expression via association with Sox9. J Biol Chem. 2003 May 5.

22. Huang W, Chung UI, Kronenberg HM, de Crombrugghe B. The chondrogenic transcription factor SOX9 is a target of signalling by the parathyroid hormone-related peptide in the growth plate of endochondral bones. Proc Natl Acad Sci USA. 2001;98:160-65.

23. Ng LJ, Wheatley S, Muscat GEO, Conway-Campbell J, Bowles J, Wright E, et al. SOX9 binds DNA, activates transcription, and coexpresses with type II collagen during chondrogenesis in the mouse. Dev Biol.1997;183:108-21.

24. Hiraki Y, Shukunami C, Iyama K, Mizuta H. Differentiation of chondrogenic precursor cells during the regeneration of articular cartilage. Osteoarthritis and Cartilage. 2001;9:S102-8.

25. Ogawa T, Shimokawa H, Fukada K, Suzuki S, Shibata S, Ohya K, Kuroda T. Localization and inhibitory effect of basic fibroblast growth factor on chondrogenesis in cultured mouse mandibular condyle. J Bone Miner Metab. 2003;21(3):145-53.

26. Wildemann B, Schmidmaier G, Ordel S, Stange R, Haas NP, Raschke M. Cell proliferation and differentiation during fracture healing are influenced by locally applied IGF-I and TGF- $\beta 1$ : Comparison of two proliferation markers, PCNA and BrdU. J Biomed Mater Res B Appl Biomater. 2003;65(1):150-6.

27. Tuli R, Tuli S, Nandi S, Huang X, Manner PA, Hozack WJ, Danielson KG, Hall DJ, Tuan RS. Transforming growth factor- $\beta$-mediated chondrogenesis of human mesenchymal progenitor cells involves $\mathrm{N}$-cadherin and mitogen-activated protein kinase and Wnt signaling cross-talk. J Biol Chem. 2003;278(42):41227-36.

28. Tsurimoto T. PCNA binding proteins. Front Biosci.1999;4:D849-D858.

29. Sharawy MM, Ali AM, Choi WS. Immunohistochemical localization and distribution of proliferating cell nuclear antigen in the rabbit mandibular condyle following experimental induction of anterior disk displacement. Cranio. 2002;20:111-115.

30. Yang Y, Topol L, Lee H, Wu J. Wnt5a and Wnt5b exhibit distinct activities in coordinating chondrocyte proliferation and differentiation. Development. 2003;130(5):1003-15.

31. Coqueret O. Linking cyclins to transcriptional control. Gene. 2002;299(1):35-55.

32. Otto WR, Rao J. Tomorrow's skeleton staff: mesenchymal stem cells and the repair of bone and cartilage. Cell Prolif. 2004;37(1):97-110.

33. Rudnicki JA, Brown AM. Inhibition of Chondrogenesis byWntGene Expressionin Vivoandin Vitro. Dev Biol. 1997;185(1):104-18.

34. Ueno T, Kagawa T, Kanou M, Fujii T, Fukunaga J, Mizukawa N, Sugahara T, Yamamoto T. Immunohistochemical observations of cellular differentiation and proliferation in endochondral bone formation from grafted periosteum:: expression and localization of BMP-2 and-4 in the grafted periosteum. $J$ Craniomaxillofac Surg. 2003;31(6):356-61.

35. Vortkamp A, Lee K, Lanske B, Segre GV, Kronenberg HM, Tabin CJ. Regulation of rate of cartilage differentiation by indan hedgehog and PTH-related protein. Science. 1996;273:613-22.

36. St-Jaques B, Hammerschmidt M, McMahon AP. Indian hedgehog signalling regulates proliferation and differentiation of chondrocytes and is essential for bone formation. Genes Dev. 1999;13:2072-86. 
37. Vortkamp A, Pathi S, Peretti GM, Caruso EM, Zaleske DJ, Tabin CJ. Recapitulation of signals regulating embryonic bone formation during post natal growth and in fracture repair. Mech DEV. 1998;71:65-76.

38. Amizuka N, Henderson JE, White JH, Karaplis AC, Goltzman D, Sasaki T, Ozawa H. Recent studies on the biological action of parathyroid hormone (PTH)-related peptide (PTHrP) and $\mathrm{PTH} / \mathrm{PTHrP}$ receptor in cartilage and bone. Histol Histopathol. 2000;15(3):957-70.

39. Alvarez J, Sohn P, Zeng X, Doetschman T, Robbins DJ, Serra R. TGF $\beta 2$ mediates the effects of Hedgehog on hypertrophic differentiation and PTHrP expression. Development. 2002;129(8):1913-24.

40. Inada M, Yasui T, Nomura S, Miyake S, Deguchi K, Himeno M, Sato M, Yamagiwa H, Kimura T, Yasui N, Ochi T. Maturational disturbance of chondrocytes in Cbfa1-deficient mice. Dev Dyn. 1999;214(4):279-90.

41. Rabie AB, Tang GH, Hägg U. Cbfa1 couples chondrocytes maturation and endochondral ossification in rat mandibular condylar cartilage. Arch Oral Biol. 2004;49(2):109-18.

42. Enomoto H, Furuichi T, Zanma A, Yamana K, Yoshida C, Sumitani S, Yamamoto H, Enomoto-Iwamoto M, Iwamoto M, Komori T. Runx2 deficiency in chondrocytes causes adipogenic changes in vitro. $J$ Cell Sci. 2004;117(3):417-25.

43. Wang W, Wang YG, Reginato AM, Glotzer DJ, Fukai N, Plotkina S, Karsenty G, Olsen BR. Groucho homologue Grg5 interacts with the transcription factor Runx2-Cbfa1 and modulates its activity during postnatal growth in mice. Dev Biol. 2004;270(2):364-81.

44. Hartmann C, Tabin CJ. Dual roles of Wnt signaling during chondrogenesis in the chicken limb. Development. 2000;127(14):3141-59.

45. Church V, Nohno T, Linker C, Marcelle C, Francis-West $\mathrm{P}$. Wnt regulation of chondrocyte differentiation. J Cell Sci 2002 Dec 15;115(24):4809-18.

46. Hwang SG, Ryu JH, Kim IC, Jho EH, Jung HC, Kim K, Kim SJ, Chun JS. Wnt-7a causes loss of differentiated phenotype and inhibits apoptosis of articular chondrocytes via different mechanisms. J Biol Chem. 2004;279(25):26597-604.

47. Luder HU. Perichondrial and endochondral components of mandibular condylar growth: morphometric and autoradiographic quantitation in rats. J Anat. 1994;185(Pt 3):587-98.

48. Tripathi T, Gupta P, Sharma J, Rai P, Gupta VK, Singh $\mathrm{N}$. Bone-specific alkaline phosphatase-a potential biomarker for skeletal growth assessment. J Orthod. 2018;45(1):4-10.

49. Cancedda RA, Castagnola PA, Cancedda FD, Dozin BE, Quarto RO. Developmental control of chondrogenesis and osteogenesis. Int J Dev Biol. 2000;44(6):707-14.

50. Gartner LP, Hiatt JL. Color textbook of histology e-book. Elsevier Health Sciences; 2006 Nov 24.

51. Carlevaro MF, Cermelli S, Cancedda R, Cancedda FD. Vascular endothelial growth factor (VEGF) in cartilage neovascularization and chondrocyte differentiation: autoparacrine role during endochondral bone formation. $J$ Cell Sci. 2000;113(1):59-69.

52. Shen G, Rabie AB, Hagg EU, Chen RJ. Neovascularization in the TMJ in response to mandibular protrusion. Shanghai Kou Qiang Yi Xие. 2003;12(2):1159.

53. Rabie AB, Hägg U. Factors regulating mandibular condylar growth. Am J Orthod Dentofacial Orthop. 2002;122(4):401-9.
54. Leung FY, Rabie AB, Hägg U. Neovascularization and bone formation in the condyle during stepwise mandibular advancement. Eur J Orthod. 2004;26(2):13741.

55. Sakamoto Y, Takano Y. Morphological influence of ascorbic acid deficiency on endochondral ossification in osteogenic disorder Shionogi rat. Anat Rec. 2002;268(2):93-104.

56. Kantomaa T, Ronning O. Growth mechanisms of the mandible. InFundamentals of craniofacial growth. CRC Press LLC Boca Raton, New York. 1997;204-289.

57. Nakano H, Watahiki J, Kubota M, Maki K, Shibasaki Y, Hatcher D, Miller AJ. Micro X-ray computed tomography analysis for the evaluation of asymmetrical condylar growth in the rat. Orthod Craniofac Res. 2003;6 Suppl 1:168-72; discussion 179-82

58. Rabie AB, She TT, Hägg U. Functional appliance therapy accelerates and enhances condylar growth. Am J Orthod Dentofacial Orthop. 2003;123(1):40-8.

59. Rabie AB, Tsai MJ, Hägg U, Du X, Chou BW. The correlation of replicating cells and osteogenesis in the condyle during stepwise advancement. Angle Orthod. 2003;73(4):457-65.

60. Chayanupatkul A, Rabie AB, Hägg U. Temporomandibular response to early and late removal of bite-jumping devices. Eur J Orthod. 2003;25(5):465-70.

61. Rabie AB, Tang GH, Xiong H, Hägg U. PTHrP regulates chondrocyte maturation in condylar cartilage. J Dent Res. 2003;82(8):627-31.

62. Rabie AB, Zhao Z, Shen G, Hägg EU, Robinson W. Osteogenesis in the glenoid fossa in response to mandibular advancement. Am J Orthod Dentofacial Orthop. 2001;119(4):390-400.

63. Tang GH, Rabie AB, Hägg U. Indian hedgehog: a mechanotransduction mediator in condylar cartilage. $J$ Dent Res. 2004;83(5):434-8.

64. Sinsel NK, Opdebeeck H, Guelinckx PJ, Guelinckx PJ. Mandibular condylar growth alterations after unilateral partial facial paralysis: an experimental study in the rabbit. Plast Reconstr Surg. 2002;109(1):181-9.

65. Kantomaa T, Hall BK. Mechanism of adaptation in the mandibular condyle of the mouse. An organ culture study. Acta Anat (Basel). 1988;132(2):114-9.

66. Kantomaa T, Hall BK. On the importance of cAMP and $\mathrm{Ca}++$ in mandibular condylar growth and adaptation. $\mathrm{Am}$ J Orthod Dentofacial Orthop. 1991;99(5):418-26.

67. Takahashi I, Nuckolls GH, Takahashi K, Tanaka O, Semba I, Dashner R, Shum L, Slavkin HC. Compressive force promotes sox 9 , type II collagen and aggrecan and inhibits IL-1beta expression resulting in chondrogenesis in mouse embryonic limb bud mesenchymal cells. J Cell Sci. 1998;111(14):2067-76.

68. Takahashi I, Mizoguchi I, Nakamura M, Kagayama M, Mitani H. Effects of lateral pterygoid muscle hyperactivity on differentiation of mandibular condyles in rats. Anat Rec. 1995;241(3):328-36.

69. Weiss A, von der Mark K, Silbermann M. A tissue culture system supporting cartilage cell differentiation, extracellular mineralization, and subsequent bone formation, using mouse condylar progenitor cells. Cell differentiation. 1986;19(2):103-13.

70. Barrer HG, editor. Orthodontics: The State of the Art. University of Pennsylvania Press; 1981.

71. Norfolk, VA: Bateson. Merida-Velasco JR, RodriguezVazquez JF, Merida-Velasco JA, Sanchez- Montesinos I, Espin-Ferra J, Jimenez-Collado J. Development of the human temporomandibular joint.1999. Anat Rec. 255:2033. 
72. Voudouris JC, Kuftinec MM. Improved clinical use of Twin-block and Herbst as a result of radiating viscoelastic tissue forces on the condyle and fossa in treatment and long-term retention: growth relativity. $A m J$ Orthod Dentofacial Orthop. 2000;117(3):247-66.

73. Fuentes MA, Opperman LA, Buschang P, Bellinger LL, Carlson DS, Hinton RJ. Lateral functional shift of the mandible: Part II. Effects on gene expression in condylar cartilage. Am J Orthod Dentofacial Orthop. 2003;123(2):160-6.

74. Hajjar D, Santos MF, Kimura ET. Propulsive appliance stimulates the synthesis of insulin-like growth factors I and II in the mandibular condylar cartilage of young rats. Arch Oral Biol. 2003;48(9):635-42.

75. Jain N, Tripathi T, Gupta SK, Rai P, Kanase A, Kalra S. Serum IGF-1, IGFBP-3 and their ratio: potential biochemical growth maturity indicators. Prog Orthod. 2017;18(1):11.
76. Tripathi T, Gupta P, Rai P, Sharma J, Gupta VK, Singh $\mathrm{N}$. Osteocalcin and serum insulin-like growth factor-1 as biochemical skeletal maturity indicators. Prog Orthod. 2017;18(1):30.

77. Fukada K, Shibata S, Suzuki S, Ohya K, Kuroda T. In situ hybridisation study of type I, II, X collagens and aggrecan mRNAs in the developing condylar cartilage of fetal mouse mandible. J Anat. 1999;195(3):321-9.

78. Rabie AB, Shen G, Hagg EU, Kaluarachchi TK. Type X collagen-a marker for endochondral ossification of the mandibular condyles. Quintessence Year Book 2000.

79. Bonen DK, Schmid TM. Elevated extracellular calcium concentrations induce type $\mathrm{X}$ collagen synthesis in chondrocyte cultures. J Cell Biol. 1991;115(4):1171-8. 